\title{
ROLE OF ULTRASOUND AS AN IMAGING MODALITY IN THE UTERINE MASSES IN A TERTIARY CARE HOSPITAL
}

\author{
R. P. Singhal ${ }^{1}$, Pardaman Singh Setia ${ }^{2}$, Kawal Preet Kaur 3 , Virinder Mohan 4 , Payal Bansal ${ }^{5}$
}

${ }^{1}$ Associate Professor, Department of Radiodiagnosis, MAMC, Agroha, Haryana.

${ }^{2}$ Assistant Professor, Department of Radiodiagnosis, MAMC, Agroha, Haryana.

${ }^{3}$ Associate Professor, Department of Microbiology, MAMC, Agroha, Haryana.

4 Professor, Department of Radiodiagnosis, ASC College of Medical Sciences, Sidhra, Jammu.

${ }^{5}$ Consultant, Prime Diagnostics, Hisar.

\begin{abstract}
BACKGROUND
In the preoperative diagnosis and management of patients with gynaecologic pelvic masses, gray scale ultrasound or computed tomography can provide significant clinical data.[1] Accurate evaluation of uterine and adnexal masses has become more feasible because of advances in imaging. Sonography is now considered an extension of the physical examination and is used as the primary imaging technique for the evaluation of any female pelvic mass.[3] Hence, this study was conducted to evaluate the role of ultrasound as an imaging modality in uterine masses in a tertiary care hospital.

Aims and Objectives-

1. To study the clinico-radiological profile of patients presenting with uterine masses by using sonography.

2. Pre-operative assessment of benign versus malignant tumours by sonography.
\end{abstract}

ABSTRACT

\section{MATERIALS AND METHODS}

This prospective study was conducted over a period of one and a half years (May 2006 to September 2007) in the Department of Radiodiagnosis and Imaging, Acharya Shri Chander College of Medical Sciences and Hospital, Sidhra, Jammu. A total of 20 patients were referred to the Department of Radiodiagnosis for the evaluation of uterine masses on the basis of high clinical suspicion. They were radiologically evaluated by ultrasound. The images were further evaluated clinically and radiologically.

\section{RESULTS}

A total of 20 patients were referred to the Department of Radiodiagnosis. They included the following cases- benign uterine masses (18) and malignant uterine masses (2).

\section{CONCLUSION}

Ultrasonography is usually the initial diagnostic examination performed in the elucidation of uterine and adnexal masses, because of superb delineation of the pelvic organs through the fluid filled urinary bladder. Thus, to conclude ultrasound is an effective imaging technique for evaluation of uterine masses and determining the consistency of the mass.

\section{KEY WORDS}

Ultrasound, Neoplastic Masses, Sonography, Uterine Mass, Uterine Cancer.

HOW TO CITE THIS ARTICLE: Singhal RP, Setia PS, Kaur KP, et al. Role of ultrasound as an imaging modality in the uterine masses in a tertiary care hospital. J. Evolution Med. Dent. Sci. 2018;7(19):2390-2392, DOI: 10.14260/jemds/2018/538

\section{BACKGROUND}

In the preoperative diagnosis and management of patients with gynaecologic pelvic masses, gray scale ultrasound or computed tomography can provide significant clinical data.[1] Ultrasound has greater ability to portray the internal consistency of the mass. Excepting the completely cystic mass, the internal consistency of the mass as depicted by ultrasound can alter or narrow the diagnostic possibility to one or two entities.

Accurate characterisation of adnexal and uterine lesions is of utmost importance in preoperative planning, because it facilitates the choice of therapy and assists the gynaecologists in the design of surgical approach.[2]

'Financial or Other Competing Interest': None.

Submission 20-03-2018, Peer Review 24-04-2018,

Acceptance 30-04-2018, Published 07-05-2018.

Corresponding Author:

Dr. Pardaman Singh Setia,

\#34, New Campus, Maharaja Agrasen Medical College,

Agroha, Hisar-125047.

E-mail: googlingisgood@gmail.com

DOI: $10.14260 /$ jemds $/ 2018 / 538$

\section{(c) $(1) \ominus$}

Accurate evaluation of uterine and adnexal masses has become more feasible because of advances in imaging. Sonography is now considered an extension of the physical examination and is used as the primary imaging technique for the evaluation of any female pelvic mass.[3]

Most of the uterine and adnexal masses have insidious onset and the patients harbouring such masses remain unaware of their presence, especially when the patient is obese. A large mass may be asymptomatic, while a small mass may produce overt symptoms especially if it becomes infected, bleeds or its pedicle undergoes torsion. ${ }^{4]}$

Both Ultrasound and Computed Tomography are effective techniques for the detection of gynaecologic masses and the evaluation of their consistency.[1]

The evolution of imaging techniques over the past few decades has continued at an astounding pace. Sonography is typically the initial imaging modality used in evaluating pelvic masses in women.[5]

On ultrasound, fibroids have a variety of appearances. They are relatively homogenous and mildly to moderately echogenic. These masses usually produce nodular enlargement of uterine outline.[6] 
According to Trenta et al, pre-operatively exact relationship between the mass and the pelvic organs can be established with ultrasound.[7]

Cochrane et al concluded that ultrasound is a safe, noninvasive examination which should be the first procedure in the workup of a patient with a definite or suspected pelvic mass. [8]

Hence, this study was conducted to evaluate the diagnostic accuracy of ultrasound as an imaging modality in uterine masses in a tertiary care hospital.

\section{Aims and Objectives}

This study was designed-

1. To study the clinico-radiological profile of patients presenting with uterine masses by using sonography.

2. Pre-operative assessment of benign versus malignant tumours by sonography.

\section{MATERIALS AND METHODS}

This prospective study was conducted over a period of one and a half years (May 2006 to September 2007) in the Department of Radiodiagnosis and Imaging, Acharya Shri Chander College of Medical Sciences and Hospital, Sidhra, Jammu. During this period, a total of 20 patients were referred to the Department of Radiodiagnosis for the evaluation of uterine masses on the basis of high clinical suspicion. All the patients underwent ultrasound examination. These included both inpatients as well as outpatients.

Detailed history was recorded as per proforma. Ultrasonography was performed using Logiq 500 PRO Series using a curvilinear probe of 3.5 to $4.5 \mathrm{MHz}$. The patient was asked to lie down in supine position comfortably on the bed with distended urinary bladder for an acoustic window. Imaging of the uterus and adnexa was performed in both transverse and sagittal planes. An oblique angulation was taken when necessary to visualise the entire uterus and cervix.

Ultrasound images were evaluated, and a differential diagnosis was reached on the basis of image characteristics, age of the patient and site of the lesion. Findings were correlated with surgical and histopathological examination, wherever possible. The images were further evaluated clinically and radiologically.

\section{RESULTS}

A total of 20 patients were referred to the Department of Radiodiagnosis for the evaluation of uterine masses on the basis of high clinical suspicion. They were radiologically evaluated by ultrasound.

Benign uterine fibroids were observed in 18 cases, while endometrial carcinoma was reported in 2 cases. On histopathological examination the 2 masses which were diagnosed as endometrial carcinoma were found to be submucosal leiomyoma.

Intramural leiomyoma was seen in 12 cases. Subserosal leiomyoma was seen in 6 cases and submucosal leiomyoma in 1 case. Hyperechoic masses were seen in 6 cases and hypoechoic in 12 cases. All were of solid echotexture.

Outline of normal uterine pear shape was disturbed, but its sharp distinct borders were identified in 12 cases. In 6 cases uterus was enlarged, its shape was deformed, and its borders were ill-defined. Out of these 3 cases were diagnosed as subserosal leiomyomas on ultrasonography, subsequently proved out to be broad ligament leiomyomas.

One case of intramural fibroid was associated with pregnancy. It was $17 \mathrm{~cm}$ in size. One case of submucosal leiomyoma was incorrectly diagnosed, which on subsequent laparotomy and histopathology proved out to be endometrial carcinoma.

MRI was performed in only 1 case. It was done to rule out the strong clinical suspicion of sarcomatous degeneration of leiomyoma in patient aged 56 years. It showed characteristic signal-intensity pattern, i.e. isointense on T1W images and hypointense on $\mathrm{T} 2 \mathrm{~W}$ images.

\section{DISCUSSION}

It is well known that pelvic disorders produce a number of common symptoms and it is difficult to identify the organ of origin. Conventional investigating modalities that use ionising radiation such as plain radiography, angiography, intravenous urography have been supplanted by newer imaging techniques in many instances. Ultrasound remains the study of choice in the initial evaluation of suspected adnexal masses because it is relatively inexpensive, noninvasive and widely available. ${ }^{[9]}$

A total of 20 patients in the age group 20 - 50 years were examined. Fibroid uterus was diagnosed in 18 cases and endometrial carcinoma was diagnosed in 2 cases. One case of endometrial carcinoma on subsequent surgery and histopathological examination proved out to be submucosal leiomyoma. Killacky et al[10] reported $94.4 \%$ fibroids in their series of 249 patients with clinical diagnosis of leiomyoma. Fibroids were multiple in 15 cases with variable symptoms, size and location. Weinreb et al[11] reported similar observation in their study. Symptoms were palpable mass, bleeding and pain. Casillas et al[12] reported similar findings.

Sonographically, we divided the leiomyomas by their location into intramural, subserosal and submucosal. We encountered 18 (75\%) intramural, 6 (25\%) subserosal and (4\%) submucosal leiomyomas. Hamm et al[13] reported that 5 to $10 \%$ fibroids arise submucosally and protrude into uterine cavity. Hyperechoic masses were seen in $6(30 \%)$, hypoechoic in $12(60 \%)$ and complex in $2(10 \%)$ cases. Similar findings were observed by Fleischer et al[14] in their series.

Outline of normal pear shape of uterus was altered in 12 cases $(60 \%)$, but its borders were distinct. Uterine enlargement was produced in $60 \%$ cases. Fleischer et al and Togasi et al[14] observed similar findings. Sonographically, fibroids have variable features depending on their fibrous and muscle contents. It also depends on their cystic degeneration. It is determined by the type and extent of degeneration (Morley et al,[15] Baltrowich et al[16]).

Nodular distortion of uterine outline or distortion of linear central echo can be caused by fibroid. The usual sonographic appearance of fibroid is a focal hypoechoic mass as contrasted with homogeneous medium level echoes of normal myometrium. Three cases diagnosed as subserosal leiomyoma subsequently on laparotomy proved out to be broad ligament leiomyomas.

One case was associated with pregnancy of 37 weeks gestation. It measured $17 * 15 \mathrm{~cm}$ and had hypoechoic echotexture. Kier et al[17] in their study of 17 pregnant patients showed 3 cases (17.4\%) of uterine fibroids. One case 
of a 60 -year-old female presenting with bleeding per vaginum showed thickened endometrium without any irregularity. So a diagnosis of submucosal leiomyoma was made, but on histopathology it came out to be endometrial carcinoma.

MRI was performed only in one case. It showed characteristic signal intensity, i.e. isointense on $\mathrm{T} 1 \mathrm{w}$ and hypointense on T2w images. It correlated with the findings of Hirack et al and Hamm et al.

\section{CONCLUSION}

Ultrasonography is usually the initial diagnostic examination performed in the elucidation of uterine and adnexal masses, because of superb delineation of the pelvic organs through the fluid filled urinary bladder. Thus, to conclude, ultrasound is an effective imaging technique for evaluation of uterine masses and determining the consistency of the mass.

\section{REFERENCES}

[1] Walsh JW, Rosenfield AT, Jaffe CC, et al. Prospective comparison of ultrasound and computed tomography in the evaluation of gynecologic pelvic masses. Am J Roent 1978;131(6):955-60.

[2] Yamashita Y, Torashima M, Hatanaka Y, et al. Adnexal masses: accuracy of characterization with transvaginal US and precontrast and postcontrast MR Imaging. Radiology 1995;194(2):557-65.

[3] Hricak H. Gray-scale ultrasound in 204 proved gynaecologic masses: accuracy and specific diagnostic criteria. Radiology 1992;130:391-7.

[4] Rha SE, Byun FY, Fung SE, et al. CT and MR imaging features of adneaxal torsion. Radiographics 2002;22(2):283-94.

[5] Lyer R. Imaging of gynaecologic malignancy. Seminars in Roentgenology 2004;39(3):428-36.

[6] Fleischer AC, James AE, Millis JB, et al. Differential diagnosis of pelvic masses by Gray scale sonography. Am J Roentgenol 1978;131(3):469-76.
[7] Trenta A, Pavlica P, Stasi G. Ovarian masses. Diagnostic ultrasound of lower abdomen. Butterworth 1985.

[8] Fleischer AC, Walsh JW, Jones HW, et al. Sonographic evaluation and role of pelvic masses: method of examination and role of sonography relative to other imaging modalities. Radiol Clin North Am 1982;20(2):397-412.

[9] Jeong YY, Outwater EK, Kang HK. From the RSNA refresher courses: imaging evaluation of ovarian masses. Radiograhics 2000;20(5):1445-70.

[10] Killackey MA, Neuwirth RS. Evaluation and management of the pelvic mass: a review of 540 cases. Obstet \& Gynaecol 1988;71(3 Pt 1):319-22.

[11] Weinreb JC, Barkoff ND, Megibow A, et al. The value of MR imaging in distinguishing leiomyomas from other solid pelvic masses when sonography is indeterminate. Am J Roent 1990;154(2):295-9.

[12] Casillas J, Joseph RC, Guerra JJ. CT appearance of uterine leiomyoma. Radiographics 1990;10(6):9991007.

[13] Hamm B, Kubik-Huch RA, Fleige B. MR imaging and CT of the female pelvis: radiologic-pathologic correlation. Eur Radiol 1999;9(1):3-15.

[14] Togashi K, Osaza H, Konishi I, et al. Enlarged uterus: differentiation between adenomyosis and leiomyoma with MR imaging. Radiology 1989;171(2):531-4.

[15] Morley P, Barnett E. The use of ultrasound in the diagnosis of pelvic masses. $\mathrm{Br} \mathrm{J}$ Radiol 1970;43(513):602-16.

[16] Baltrowich OK, Kurtz AB, Pasto ME. The spectrum of sonographic findings in haemorrhagic ovarian cysts. Am J Roent 1988;151:725-8.

[17] Kier R, McCarthy SM, Scout LM, et al. Pelvic masses in pregnancy: MR imaging. Radiology 1990;176(3):70913. 